\title{
DA LITERATURA AO CINEMA: UM PANORAMA \\ DA ORIGEM À CONSOLIDAÇÃO DO \\ DISCURSO IDENTITÁRIO ITALIANO
}

\begin{abstract}
From literature to cinema: an overview of the path from the origin to the consolidation of the Italian identity discourse
\end{abstract}

Julia Scamparini*

\begin{abstract}
RESUMO
Através de um panorama da produção discursiva sobre a identidade italiana a partir da Unificação, procura-se mostrar que certos temas - tais como a religiosidade, o caráter, a política e a cultura do italiano - são constantes, presentes em textos verbais, visuais e sincréticos, e se mantêm alicerçados em uma perspectiva negativa, inaugurada no Trecento, por parte de seus sujeitos enunciadores. Acredita-se que a força desta rede discursiva contribui para a manutenção de um estado de mancanza denunciado e lamentado até hoje por artistas e pensadores que refletem sobre a Itália.
\end{abstract}

Palavras-chave: Itália; identidade; discurso.

\begin{abstract}
Through a panoramic analysis of the discursive production about the Italian identity since its Unification, we try to demonstrate that certain subjects - such as religion, politics, the character and the culture of the Italians - are constant, present in verbal and visual texts, and are always negatively

*UFRJ.
\end{abstract}


approached by its authors. We believe that the strength of this discursive network contributes to the state of mancanza highlighted by artists and thinkers that reflect about Italy until today.

Keywords: Italy; identity; discourse.

1 .

Estudar ou comentar a identidade italiana, a nacional e as regionais, é um tema caro tanto a intelectuais e acadêmicos como ao homem comum. O estudo sobre a identidade italiana é oficializado como investigação acadêmica depois da Unificação da Itália, em 1861, mas a origem da discussão sobre o tema é reconhecida em textos antigos e nasce oficialmente em Dante Alighieri, Francesco Petrarca e Giovanni Boccaccio (FERRUCCI, 1993), cujos escritos descreviam, discutiam, e criticavam ou louvavam sobretudo o caráter do italiano. Sem que sejam aqui devidamente analisados, pode-se afirmar que seus textos funcionam como origem tanto do hábito de discutir a Itália, difundido em toda a península inicialmente por Dante - que "deu início ao filão oratório que chega até nós: o falar da Itália como o falar mal da Itália" (ibid., p. 16) -, bem como origem de uma literatura que viria a ser impegnata, engajada na tomada de posição em prol da difusão de traços protonacionalistas, que não prescindiria do que é considerado autêntico do país nem tampouco do que deveria ser transformado em tradição.

A força da língua escrita e a forma permanente do livro impresso desde 1447 não somente ajudaram a cristalizar as línguas nacionais, mas contribuíram para o estabelecimento de linguagens de poder, dentre as quais figura a literatura (ANDERSON, 2005). Um dos traços culturais universalmente reconhecido como autenticamente italiano é exatamente a contribuição literária de Dante, Petrarca e Boccaccio, fundamentais para a fixação do latim vulgar e de uma língua italiana escrita, literária, ao lado de outras importantes publicações no século XVI, ${ }^{1}$ além de esses escritores terem inaugurado a discussão sobre a Itália e sobre o italiano - uma criação exclusivamente literária, segundo Ferrucci (1993).

Se se parte da premissa de que Dante inaugurou a crítica ao italiano, devemos aceitar que tal hábito foi gloriosamente retomado por Giacomo

${ }^{1}$ São quatro as datas fundamentais da história do desenvolvimento da língua italiana. 1501 é o ano da publicação da edição Aldina de Petrarca, organizado por Bembo, com especial cuidado com a ortografia. Em 1525 saíram as Prose della vulgar lingua, também de Bembo. 0 ano de 1582 é a data tradicional da fundação da Accademia della Crusca. Já no século XVII, 1612 é o ano da primeira edição do Vocabolario degli Accademici (REIS, 1997, p. 33). 
Leopardi, ${ }^{2}$ e é a partir dele que grande parte dos estudos sobre as reflexões e construções literárias do italiano geralmente se concentram (FERRUCCI, 1993; RAIMONDI, 1998), ou, se partem da época em que a Itália já era unificada, ao menos mencionam a sua importância como fonte inspiradora (BOLLATI, 1983). Leopardi escreve vinte anos após a Revolução Francesa, localizando-se em uma época em que se constituem novos instrumentos de interpretação do mundo moderno, e, portanto, tem consciência de que é testemunha do início de um caminho em direção à reconstrução da sociedade. Assim, ainda que não tenha conhecido muitas, ${ }^{3}$ descreve e defende sua concepção de società stretta, à qual a italiana não corresponde: movida pelo individualismo, a società stretta destrói a igualdade e faz crescer a disparidade, mas, apesar disso, é fundamental para a modernização da nação. Conforme diz Raimondi (1998, p. 135):

A tese de Leopardi havia já sido anunciada: acabara o mundo dos grandes valores, aqueles que chama de valores antigos, não os da Idade Média, mas os do mundo antigo, uma grande ética da glória e do valor, das grandes iniciativas, dos grandes sonhos, da grande imaginação.

Apesar de descrever a Itália como um país que "por natureza quer vivacidade, extroversão, [...] o amplo sentido de espetáculo, invenção, que é disposto ao máximo fervor, à máxima capacidade inventiva, a construir", a julga uma sociedade "onde, ao contrário, o que vale é a apatia e a indiferença [...] desprovida das características da società stretta e íntima" e sua gente um "povo meridional por excelência, expansivo, coloquial, mas sem a verdadeira conversação" (LEOPARDI, 1993, p. 138).

Raimondi (1998) afirma que Leopardi não é moralista, mas toma o discurso de um moralista moderno no sentido vigente nos séculos XVII e XVIII, que é aquele que fala dos costumes e examina o comportamento dos homens. Com esse objetivo subjacente, Leopardi enuncia seu juízo sobre a opinião pública, o cinismo, a indiferença, e a falta de costumes do povo italiano no Discorso sopra lo stato presente degli italiani, de 1824 , e no Zibaldone, escrito de 1817 a 1832 :

Primeiramente, os italianos em geral, e principalmente com relação a outros povos, não levam em consideração a opinião pública. entre outros.

${ }^{2}$ No Discorso sopra lo stato presente degli italiani e no Zibaldone (in FERRUCCI, 1993),

${ }^{3}$ Leopardi jamais saiu da Itália, onde conheceu Bologna, Florença, mas nem mesmo Roma (FERRUCCI, 1993), o que acentua o caráter discursivo, muito mais do que empírico, de suas reflexões. 
o mais sábio recurso é o de rir indistintamente e habitualmente de qualquer coisa e de qualquer pessoa, começando de si mesmo.

Nasce daquelas disposições a indiferença profunda, enraizada e muito eficaz com relação a si mesmo e aos outros, que é a maior peste dos costumes, do caráter e da moral.

Os italianos têm mais usos e hábitos do que costumes.

Ao contrário dos hábitos, os costumes, para Leopardi, estão ligados ao passado e são aceitos como fato de responsabilidade pessoal, e, uma vez que os italianos não os têm, verifica-se no país "o enfraquecimento dos princípios morais", fazendo dos italianos mais "indisciplinados e imorais em sua conduta" do que os povos que têm como característica a società stretta. A Itália só reparará esta situação se conseguir tornar-se moderna (RAIMONDI, 1998, p. 137). Em suma, explica a não inclusão da Itália na modernidade porque a julga "meridional" e herdeira da antiga civilização clássica, o que se coloca contra a necessária frieza da realidade moderna. (FERRUCCI, 1993, p. 160). Leopardi, pode-se concluir, é o precursor da escrita sobre a cultura com fins políticos, bem como da escrita que indaga os motivos da ausência de modernidade e as possibilidades de mudança deste quadro na sociedade italiana.

Ainda no âmbito da discussão do comportamento do povo italiano, Alessandro Manzoni escolhe outra direção, também vinculada a fins políticos. Liberal-revolucionário, porque herdeiro do espírito da Revolução Francesa, e católico convertido, já em 1815 definia sua concepção de nação moderna: "uma de armas, de língua, de altar, de memória, de sangue e de coração" (apud RAIMONDI, 1998, p. 150).

Língua comum, princípios cristãos, origem histórica, união política. São esses os elementos que estarão subjacentes aos seus escritos, das Osservazioni sulla morale cattolica (1819) à Storia della Colonna Infame (1840), até a instauração da utopia da "sociedade benevolente", a qual se lê nas entrelinhas de I Promessi sposi (1842). Com este romance, Manzoni tinha a intenção de construir uma história cristã com personagens que não constituíam somente parte da narrativa, mas eram principalmente portadores de valores do evangelho, fazendo do livro um "projeto religioso, providencialista [...] luz divina que chega para resplandecer este mundo" (ASOR ROSA, 1997, p. 603), instituindo para o povo um esquema de comportamento adequado. Além deste projeto, em Manzoni reconhece-se uma "visão de sociedade orgânica de fundo agrícola, depositária de todos os valores da tradição e baseada na 
benevolência de todos para todos", o que atesta sua defensiva pela desejada ordem e contra os perigos revolucionários (BOLLATI, 1983, p. 91).

As obras infantis Le avventure di Pinocchio (1881), de Carlo Collodi, e Cuore (1886), de Edmondo De Amicis, também são reconhecidas como agentes promotores de um comportamento padrão, já que foram publicadas pouco tempo após a unificação da Itália e contêm um projeto pedagógico, segundo Asor Rosa (1997):

Por um lado, na verdade, há um mundo natural, um mundo feito de impulsos incontroláveis, de dispositivos de fuga do perigo, do medo, da violência e de desejos elementares: não querer estudar e não querer trabalhar significa simplesmente colocar-se um objetivo anti-social ou a-social, recusar o casamento com a civilização constituída, com as hierarquias dos deveres, dos direitos reconhecidos. O termo justo para esta escolha de vida [...] é usado por Pinocchio logo no início: "vagabundo". (p. 598)

O projeto pedagógico de De Amicis trabalha em sintonia com a sociedade circundante: ela se mostra incompleta e atrasada em relação ao seu projeto, mas não faltam as condições para delinear a médio prazo uma solução harmônica. (p. 599)

Assim, em ambas está aplicado o código moral representante de um esquema extremamente católico:

A desordem, a longo prazo, acarreta dano; é preciso enquadrar-se como se deve, porque caso contrário os riscos são de punições sociais pesadíssimas; ter bom coração significa respeitar e amar o papai e a mamãe, não roubar, ajudar aqueles que estão piores do que nós, lutar com decisão pela sobrevivência, não dar ouvidos aos maus professores e nem às más companhias. (ASOR ROSA, 1997, p. 559)

Da mesma época, I Malavoglia (1881) trata de um protesto marcado pelo rebelismo social, não tem projeto religioso, e contém em sua narrativa a metáfora do "punho fechado" e seu princípio de unidade e hierarquia: o dedo grande deve ter a função de dedo grande, o dedo pequeno deve ter a função de dedo pequeno. Giovanni Verga é o representante maior do Verismo, vertente italiana do Naturalismo europeu que procurava fazer da página literária um “documento humano" (RONCORONI, 1985, p. 240). Ao comparar a obra de Verga e o romance I promessi sposi, Asor Rosa (1997) afirma que são ambos "contos de infortúnios": no I Malavoglia, os problemas são uma 
lição de vida para os pobres; no livro de Manzoni, são úteis para uma vida melhor. Na obra de Verga está subjacente uma ideologia diferente, que trata de problemáticas italianas sob uma ótica menos ideal.

A igreja católica talvez seja o mais indiscutível e marcante traço constitutivo da identidade italiana. Após o insucesso da tentativa de união nacional através da língua, no Cinquecento, era o catolicismo o elemento que dava aos italianos o sentimento de fraternidade nacional. Mas, apesar da natural religiosidade itálica, a busca pela identidade fundada no catolicismo também não foi bem sucedida, já que o Vaticano se manteve nação independente da Itália com a unificação. O sentimento de identidade nacional seria originado e difundido popularmente somente no século seguinte, durante o fascismo e, depois, com a Resistenza.

Fazendo uso dos instrumentos de identificação secularmente tradicionais - o catolicismo e a língua -, no século XIX Manzoni contribuía para a difusão de certa subordinação católica: que o homem "abandone o orgulho de acreditar ser a fonte da moral, abdique da presunção de ser o criador do próprio destino, e se incline à única lei certa e imutável, aquela revelada por Deus" (BOLLATI, 1983, p. 83). E para sua Roma católica, buscou a união linguística usando em seu romance uma língua mais disponível a todos, próxima à falada; e também sugerindo o toscano como língua nacional e maneiras de ensiná-la, em seu Dell'unità della lingua e dei mezzi di diffonderla, em 1868.

Giosuè Carducci, por sua vez, foi um literato em serviço patriótico disposto a fazer de sua obra um lugar para a continuidade dos valores risorgimentais e clássicos, cuja escrita procurava, também através da métrica, comunicar sua nostalgia por um mundo de beleza e liberdade. Esse mundo, localizado temporalmente na Idade Média, era, para o poeta, o contrário do que prefigurava o mundo moderno, o qual considerava de mesquinhez, "decadência e morte" (GIOANOLA, 1985, p. 112).

Em suma, desde o século XIX até o primeiro meio século de união italiana, configurou-se um discurso sobre a identidade herdeiro de um costume de se falar da Itália e do italiano, inaugurado no Trecento. Esse discurso permeou a literatura e o pensamento da época, e pode ser considerado uma forte arma para a divulgação do estereotipo sócio-cultural e político que se esperava do povo italiano. Após a unificação, inevitavelmente, tal discurso ultrapassa o campo da literatura e da filosofia e se liga, mesmo quando não institucionalmente encomendado, ao nacionalismo e ao protonacionalismo, ${ }^{4}$

${ }^{4} \mathrm{O}$ protonacionalismo refere-se ao uso de elementos culturais usados como símbolos de união nacional para que um povo entendesse que era um "povo-nação", e para que finalmente se consolidasse o estado-nação (HOBSBAWM, 2002). 
ou seja, ao propósito de se estabelecer a ideia de uma nação para seu povo e, em consequência, de definir uma nação mais forte no quadro europeu.

O mais polêmico nacionalismo italiano - alimento da ideologia do período fascista de governo - promoveu um renascimento e morte do sentimento de pátria: deu vida aos ideais do Risorgimento e os liquidou com o fim da $2^{\text {a }}$ guerra mundial. Os vinte anos de fascismo ligam-se à discussão sobre o discurso da identidade italiana porque, em nome desse nacionalismo, foi promovido o sentimento de confiança e subjugação à pátria acima de tudo, através da difusão da esperança por um bem estar baseado em modelo estrangeiro e pela retomada do código moral católico, usando o primeiro como projeção de uma Itália que todos desejavam, e a religião como elemento de identificação cultural ligado à tradição. Nesse momento histórico, também devido aos tipos de recursos midiáticos que atingiam muito mais facilmente a massa popular - o cinema e o rádio, que tinham uma considerável porcentagem da população como espectadora e ouvinte -, o vínculo entre o que é político e cultural tenha chegado ao seu mais alto nível. Assim, o uso do cinema contribuiu para a concepção mais "inventada" sobre a Itália que seu povo testemunhou até hoje porque levou os italianos a se sentirem semelhantes em relação ao chefe de estado, apesar de não os ter ajudado a se identificarem a longo prazo como italianos (SORLIN, 2004). A passagem pelo fascismo assinalou mais uma falência na tentativa de construir coordenadas unitárias de uma existência coletiva, pois "não bastavam os prefeitos, o exército, a escola e as estruturas repressivas para 'fazer os italianos'” (DE LUNA, 2004, p. 26); era necessário que algo mais fosse feito no campo da cultura e, sobretudo, no campo da política. E seria a Resistenza, motivada por valores de solidariedade, justiça e democracia, o movimento responsável por conferir ao povo italiano o mais forte sentimento de identidade após a ilusão fascista.

Ao contextualizarmo-nos em outra época, vale dizer, o pós-guerra, estabelece-se um recorte temporal que, segundo nossas hipóteses, é característico de uma redefinição do discurso sobre a identidade italiana. Inaugurados simbolicamente pelo armistício de 8 de setembro de 1943 , o sentimento de novo Risorgimento e os valores da Resistenza renovaram o pensamento e, consequentemente, os enunciados ligados à nação e à sociedade italiana. o discurso que está em voga na época muda em sua motivação, em relação aos assuntos que aborda, aos pontos de vista que defende, ou seja, muda com respeito à ideologia que o leva adiante. Trata-se de uma (re)tomada da perspectiva sócio-antropológico-cultural da disciplina, menos ligada a empenho político do que fora até então. O empenho político está presente nos novos textos, mas das mãos dos agentes oficialmente ligados à política, passa àquelas dos indivíduos ligados às artes e à academia. A função do 
discurso é outra, os sujeitos são outros, bem como os enunciados; os temas, porém, são retomados ou apenas atualizados: fala-se de novos hábitos mas também dos costumes tradicionais, do catolicismo e do sentimento de religiosidade, da história, de política, do caráter. No âmbito das artes, torna-se protagonista o Neorrealismo e, principalmente, o cinema desta tendência. A guerra e a situação italiana depois dela, e todas as decepções e derrotas trazidas pelo fascismo, podem ser consideradas as molas propulsoras de uma nova maneira de se ver, conceber e falar sobre o país.

Após a $2^{\text {a }}$ grande guerra, a Itália tornou-se República e cresceu industrial e economicamente, e foram essas as mudanças imediatas que acabaram por reconfigurar a realidade do país. A mudança política e a história mundial, sobretudo russa, davam novas possibilidades de organização político-social, e a injeção de fundos para a recuperação do país promovida pelos Estados Unidos tornou possível uma mudança nos costumes, uma vez que se podia consumir mais. Em seguida, o advento da televisão, nos anos 1950, contribuiu para o estabelecimento da chamada cultura de massa, que homogeneizaria opiniões e difundiria novos hábitos culturais (GINSBORG, 1989). Este contexto de mudança promoveu não somente manifestações culturais que discutiam um novo estereótipo do italiano e seus costumes, bem como investigações sociológicas (SORLIN, 1979; BRUNETTA, 1996; CAVALLO; FREZZA, 2004; ALPINI, 2008) que estudavam este novo país e povo, principalmente no que diz respeito ao cinema.

Contemporaneamente, emergem estudos que investigam a invenção da Itália e do italiano, isto é, que investigam a construção literária e política da comunidade transformada em nação, e do homem transformado em cidadão. Estudos sociológicos ou históricos que se interessam exatamente pela construção discursiva presente em Leopardi, Manzoni, Verga e outros, e nos mitos de língua, de comportamento, e de organização social que eles imaginaram como símbolos ideais para a história da Itália unificada.

No âmbito da História, alguns dos trabalhos que optam por localizar sua investigação cronologicamente no período entre a Revolução Francesa e a unificação italiana procuram entender como foi difundida a ideia de nação. Bollati (1983) conta que o italiano foi "descoberto" pelo conde Paolo Greppi, um general que se deu conta de que era preciso massa humana para que as fronteiras da Itália fossem defendidas dos franceses revolucionários: sacrificar-se pela pátria foi o início da consciência dos habitantes da península de que faziam parte de uma comunidade comum. Assim, antes e depois da unificação, os "engenheiros de italianidade", expressão bollatiana, agiam na educação e caracterização do povo, como Vincenzo Cuoco, cujos dizeres "Agricultura e virtude! Isso não basta para fazer um povo feliz?" ou "Virtude? Encontra-se somente nos campos" o tornaram responsável por 
uma reviravolta ideológica de grande dimensão na época. Segundo Bollati (1983, p. 62), ele é:

[...] o inventor-descobridor do arquétipo de uma Itália que extrai saúde e vigor das profundas raízes de sua antiga civilização camponesa, uma Itália anti-intelectual que despreza os refinamentos culturais decadentes da idade moderna, e tem orgulho da sua notabilidade autóctone, de seu antigo costume moral.

Enquanto Bollati observa que Cuoco reforçou o caráter camponês do italiano e que Manzoni, como vimos, contribuiu para a difusão de ideais de comportamento católico, Di Ciommo (2004) investiga outros textos que tinham como projeto a criação de uma identidade nacional, como, por exemplo, os escritos políticos de Mazzini, que tinham função de educação de ideais civis.

Por sua vez, De Mauro (1983) trata da história linguística da Itália unificada examinando a divulgação de uma língua homogeneizante na literatura de Collodi, de De Amicis, e de Manzoni, bem como a heterogeneidade dialetal exposta por Verga. Além disso, descreve o papel do rádio, do jornal, da musica leggera, do cinema, entre outros fenômenos midiáticos, e, finalmente, o papel da televisão, principal ferramenta para a difusão do italiano nacional.

Estes e outros escritos acadêmico-investigativos, como o exame da relação entre escritos literários e filosóficos e a identidade nacional empreendido por Raimondi (1998), deixam claro que a esfera de obras analíticas que discute a identidade italiana compreende textos políticos, literários e linguísticos, que se aproximarão a escritos artísticos e sociológicos pela repetição e divulgação de aspectos da história e da "italianidade" da península.

\section{2.}

O discurso da identidade da Itália e dos italianos ultrapassou os limites da escrita e invadiu as artes visuais. Observada no interior de sua evolução - considerado um recorte histórico iniciado com a unificação -, bem como examinada a arte que era produzida como resultado de encomenda, muitos dos temas tomados pelos textos escritos até aqui investigados são repetidos, ainda que em linguagem outra, visual, ou mesmo sincrética, como a cinematográfica. Dos murais encomendados para a figuração das 
guerras pela união, aos filmes finalizados a divulgar uma imagem de bem estar proposta pelo regime fascista (BRUNETTA, 1991, MESSINA, 1997); das motivações futuristas em prol do rompimento com os padrões clássicos, e também contra a desumanização resultante do processo de maquinação da mão de obra (BOLLATI, 1983), às temáticas dos filmes neorrealistas, nunca estiveram completamente ausentes os aspectos da identidade italiana que vislumbramos organizados em discurso. Em outras palavras, outras linguagens foram utilizadas para tal testemunho, quando ambicionado pelas instituições promotoras do senso de pertencimento, como também quando resultado de manifestação artística, muitas vezes compromissada com uma ideologia, mas não vinculada ao poder do estado.

Nos murais destinados a representações de regime - monárquico ou fascista - figuram imagens agregadoras e mitos legitimadores e fundadores, como batalhas históricas, principalmente, as quais eram encomendadas para a decoração de salas ilustres. Em Siena, Roma ou Veneza, vê-se as respectivas vitórias que, de uma forma ou outra, ajudaram no objetivo de unificação. Sua representação instaura uma temática histórica e uma poética do real, realista ou verista (ver MESSINA, 1997, p. 100).

Mas é característico desta época um desencontro entre ideais nacionais e uma arte regionalista, visto que as imagens da vitória nacional produzidas por encomenda acabavam por expor as vitórias locais. Esse regionalismo permanecerá vigente por cerca de um século, devido, por exemplo, a uma certa institucionalização do mesmo: a Bienal de Veneza e a Galleria di arte moderna de Roma foram por muitos anos organizadas por regiões. A tese de Messina é a de que esse regionalismo tanto afastou a arte como instrumento de uma representação política nacional, como também impediu que fosse configurada uma arte moderna italiana, frente à arte europeia.

O regionalismo é alimentado pela poética do verismo de tal forma a ser relançado e consagrado, no plano iconográfico e formal, pela então veemente afirmação dessa poética. As exposições Nacionalistas estão lotadas de cenas do gênero ou de paisagens rurais, as quais fundam a atração que exercem no público em uma verdade antropológica, geográfica, e até mesmo climática. (1997, p. 107)

Embora em desacordo com os ideais nacionalistas, o discurso da identidade italiana se mantém, através de uma narrativa já um pouco atualizada, a qual toma como objetos a história recente da península, mas que também é conservadora. Segundo o que escreve o crítico Gnoli nos anos 1890, para que a arte da península estabelecesse uma identidade própria e se tornasse realmente italiana, deveria ser fundada "a partir do modelo já 
revisto pelos pré-rafaelitas, ou seja, pela retomada de um espiritual florentino dos 400, de beato Angelico a Botticelli” (MESSINA, 1997, p. 108). Ou seja, a retomada da cultura italiana consolidada, outro elemento do discurso em questão, não é abandonada, ainda que no fim do século XIX:

Caísse todo o universo dos fundamentos, o firmamento dos a priori, o céu dos absolutos que haviam modelado a civilização europeia entre o iluminismo setecentista e a expansão industrial dos Oitocentos. (CERRONI, 2000, p. 79)

No início do século XX, o movimento futurista queria fazer da Itália um grande país moderno, e para isso procedeu a um rompimento histórico-cultural decisivo com o Ottocento, isto é, com o romantismo literário e político, com o impressionismo pictórico, com o neoclassicismo arquitetônico (CERRONI, 2000). Contudo, quis modernizar a Itália "no antigo sentido e pela antiga via italiana: moralista [...] idealista, espiritualista, narcisista, estetizante" (BOLLATI, 1983, p. 118). Assim, o futurismo rompe no que se refere à estética, à linguagem pictórica e aos ideais que difunde, como se pode ver na pintura de Umberto Boccioni, e nos escritos de Marinetti, por exemplo, mas sem abandonar a "ininterrupta gestão conservadora" italiana (BOLLATI, 1983, 119). O testemunho de Carlo Carrà sobre o futurismo, ainda que dado em momento de afastamento da tendência, atesta a continuidade de uma linha de pensamento que nunca abandonou a arte italiana: o artista defende que a arte italiana será mais potente e certa de seu destino se houver a aceitação da doutrina clássica proposta em outras ocasiões, coordenando assim os valores típicos da estirpe (BOLLATI, 1983, p. 123).

Depois das tentações vanguardistas, a intenção de manter tal continuidade é de novo reconhecida no que se refere à temática artística antiga, e pode ser comprovada pela introdução do catálogo da Bienal de 1930: procurava-se "criar condições para a retomada das gloriosas tradições" da arte do Renascimento e de oferecer incentivos aos artistas, para que pudessem "colocar-se novamente em contato com a grande alma do povo" (MESSINA, 1997, p. 111). Neste contexto, os murais fascistas retomam temas como o mito do ruralismo, a Roma latina e mediterrânea, e o espiritualismo católico.

Além do muralismo, ${ }^{5}$ o ventennio fascista contou com o uso de uma arte até então recente, o cinematógrafo. O cinema foi instrumento de propaganda através da obrigatoriedade da projeção dos cinegiornali, de 1926 a 1938, antes dos filmes. No que se refere ao conteúdo, o fascismo

\footnotetext{
${ }^{5}$ Ver "Manifesto della pittura murale del 1933" em Messina (1997).
} 
era apresentado como grande provedor de elementos de vida moderna, como sinônimo de progresso e, ao mesmo tempo, como defensor de valores tradicionais autênticos, relacionados ao cristianismo e à família, em busca de uma identidade italiana "pura" através da censura a filmes estrangeiros e ao uso de dialetos, por exemplo, priorizando a língua inaugurada com a unificação. Na mesma época, o cinema dos telefoni bianchi também apresentava um caráter de fuga da realidade cotidiana pela celebração implícita de ideais de vida burguesa, e é considerado por alguns críticos como a expressão mais nefasta do projeto político do regime fascista, o qual necessitava do conformismo da classe média (BRUNETTA, 1996).

Com o fim da segunda guerra, tem início uma época que será caracterizada por um novo paradigma de comportamento, principalmente:

A Itália se apresenta como um país "sem": sem presente, sem impulso para o futuro, sem paisagem, sem identidade, sem capacidade comunicativa, sem capacidade de se renovar, sem vários elementos de reconhecimento. Um país intangível, incapaz de recriar interesses comuns, orientado para um irrefreável e crescente processo de degrado ideal, ambiental, humano, moral, econômico. Um país desunido, desagregado em seus gânglios mais vitais, em que cada elemento positivo do passado se converteu em elemento de oposição - como na reescrita pasoliniana das poesias da Meglio Gioventù - ou foi apagado. (BRUNETTA, 1996, p. 62)

É então que ganha força o Neorrealismo, uma vez que sua ideologia unia cineastas pela procura dos valores essenciais da existência e da convivência social, impulsionados pela revolta contra o fascismo, seu horror e suas consequências, e em busca de um engajamento que denunciasse tudo isso. A ética do movimento buscava expor a realidade provinciana, a marginalização, o desemprego e a injustiça em relação ao sul rural, lugar em que se encontraria, segundo os filmes, uma opção moral próxima aos valores tradicionais, e oposta ao que a guerra levara ao país. A abordagem de motivação ideológica neorrealista buscava centrar na veracidade dos eventos representados, e sua busca pela autenticidade da representação superou a temática dos filmes e atingiu suas escolhas estéticas e linguagem, caracterizadas por filmagens em preto-e-branco, em ambientes externos e com atores não profissionais, o que contribuía para a ênfase dramática que o movimento buscava, além de colocar nas telas também as falas regionais. ${ }^{6}$

' Os diálogos de Roma città aperta (1945), de Rossellini, mostram a multiplicidade linguística italiana através da presença inegável dos dialetos, assim como em La terra trema (1948), de Visconti. 
Era, portanto, um projeto artístico motivado pelo interesse comum e consciente da heterogeneidade da identidade italiana e, ao mesmo tempo, uma denúncia social e política. Em termos de "assuntos, esperanças, necessidades, aspirações e interesses da gente comum” (BUSSI; LEECH, 2003, p. 10), o cinema neorrealista representava e alimentava o sentido de identidade nacional a partir, portanto, de outra perspectiva.

$\mathrm{Na}$ arte pictórica, uma corrente de realismo foi representada por Renato Guttuso, motivado por ter testemunhado pessoalmente as dramáticas condições de vida dos camponeses sicilianos. Também o seu tratava-se de um realismo popular, isto é, de um realismo "mitologizante, celebrativo, ativo, direto à ação, todo cheio de movimento e de esperança” (MESSINA, 1997, p. 121), como se pode ver no quadro de 1950, Occupazione di terre incolte in Sicilia, e não de um realismo idealista, como fora o dos murais da unificação.

Era uma época em que a ideia de povo estava em voga e foi reforçada com a publicação de Letteratura e vita nazionale, de Gramsci, e que ainda que de formas diversas, o marxismo dominava o pensamento de muitos italianos. Esta ideologia foi um suporte para a arte italiana que, com o escopo de definir uma identidade mais forte frente às vanguardas europeias, reafirmou mais uma vez sua opção realista. No âmbito do cinema, essa escolha durou até o fim da década de 1950, quando da perspectiva histórico-social os cineastas passaram a concentrar a própria pesquisa e esforços em uma fenomenologia mais ligada ao indivíduo e aos seus problemas existenciais (BUSSI, 2003).

Na representação dos eventos, o cinema, melhor do que a linguagem verbal, pode permitir-se conjugar um olhar local (os personagens, por exemplo) e um olhar autoral (câmera), e, portanto, dois ou mais pontos de vista, duas ou mais histórias, com todas as implicações narrativas, estilísticas e ideológicas contidas nesta possibilidade." (BUSSI; LEECH, 2003, p. 23)

Porque ainda configurava uma nova linguagem e uma nova arte, o cinema passou a sofrer investigação com respeito à sua representação da identidade italiana. Neste momento, mais do que investigar o impulso institucional que usou o cinema como ferramenta, torna-se característico um outro olhar, menos político e mais sociológico, sobre o italiano e a Itália, nas telas. São estudos que serão a fonte das reflexões das comunidades imaginadas de Benedict Anderson (1993), por exemplo, como também de Hobsbawn e Hanger (2002), devido à necessidade de um sentido de pertencimento por causa do novo contexto cultural das complexas sociedades modernas, mais do que devido a exigências de natureza histórica ou eminentemente 
funcionais. ${ }^{7}$ Além disso, devido também à necessidade de observar a "invenção" da nação não no nível da construção de um sentido de identidade burocrático-estadual, mas em um nível mais difuso, concentrado nas práticas culturais dos indivíduos (BUSSI; LEECH, 2003), pois "é indiscutível o papel desde sempre conferido às artes na definição de uma identidade nacional no plano do imaginário coletivo, e de uma consciência civil dividida pelo pertencimento unitário" (MESSINA, 1997, p. 100).

3.

A atualidade do tema identidade, promotor de tantas publicações em todo o mundo (HOBSBAWN, 2002; HOBSBAWN; RANGER, 2002; HALL, 2004; ANDERSON, 2005; BAUMAN, 2005; entre outros), também se observa na Itália, sobretudo a partir dos anos 1980 (BECHELLONI, 1991; BOLLATI, 1983; BERTELLI, 1997; BRUNETTA, 1996, CESARIO, 1990; CERRONI, 2000; CRAINZ, 2005; DELLA LOGGIA, 1998; DI CIOMMO, 2004; FERRAROTTI, 1997; FERRUCCI, 1993 etc.). O avanço da tecnologia no fim do século XX ampliou em grandes proporções a mescla cultural global, o que fez com que as nações sentissem a necessidade de reafirmar sua identidade sociocultural em uma época em que se fala de identidades fragmentadas ou líquidas, em que se eleva e se lamenta a possibilidade de troca de identidade subjetiva a depender da necessidade e do desejo (BAUMAN, 2005; RAJAGOPALAN, 2003). A Itália, além de fazer parte da crise mundial identitária, conta também com a motivação de sua história republicana de pouco sucesso, ${ }^{8}$ como criticam seus historiadores. Em mais um momento de consciência intelectual quanto à constatação de que o país não foi bem sucedido em seu objetivo de nação moderna frente a outras realidades europeias, muitos escritos investigam o passado político da Itália, ${ }^{9}$ e muitos deles acabam por concluir que os aspectos culturais - aqueles dos quais já falavam direta ou indiretamente Dante e Boccaccio - configuram a origem do insucesso italiano, pois são, em sua substância, incompatíveis com os ideais de sociedade moderna alcançada por nações vizinhas. Fazem pensar a uma sutil retomada do Discorso sopra e Ranger (2000).

${ }^{7}$ Linha de pensamento de Ernest Gellner em Nações e nacionalismo, segundo Hobsbawn

${ }^{8}$ Os escritos de historiadores sobre a identidade italiana geralmente acusam o insucesso econômico e político da Itália, um país que consideram marcado pela corrupção, pela máfia e pela desvantagem econômica frente às outras nações europeias.

${ }^{9}$ Conferir referências precedentes no parágrafo. 
lo stato presente degli italiani de Leopardi, que, como visto, responsabilizava o caráter do povo da península pela sua incapacidade de se transformar em uma società stretta. Ou seja, é nos clássicos da literatura que também tem início a discussão sobre a conhecida "mancata modernità" italiana, a modernidade nunca alcançada tão em voga nos escritos políticos mais recentes.

A atuação política na Itália a partir de sua unificação é considerada quase unanimemente corrupta, e nunca adaptada ao que se entende por mundo moderno. Em geral, as investigações de historiadores têm como motivação a tentativa de entender e explicar essa falta de modernidade da Itália. Alguns culpam o catolicismo e o familismo, sempre ligados à política porque intrincados à cultura da península (DELLA LOGGIA, 1998). Outros tentam explicar esta ausência pelo fato de não ter acontecido na Itália uma reforma religiosa, como houve na Alemanha, ou uma revolução política, como se deu na França (FERRAROTTI, 1997, p. 121). A contrarreforma acabou por configurar uma "religiosidade quase sempre formal, ritualista, que não se responsabiliza, no fundo, vazia" (DELLA LOGGIA, 1998, p. 54), e a unificação foi descentralizada e evidenciou desigualdades já conhecidas, como aquela entre o Norte e o Sul:

O núcleo da identidade italiana não é a nação no sentido moderno. É o grupo primário, tipificado pela família, os amigos, e os amigos dos amigos; não a lei explícita [...] mas o espírito de máfia. (FERRAROTTI, 1997, p. 113)

Já outros historiadores procuram, optando por outra ótica, mostrar que a Itália não foi exatamente mal sucedida no que diz respeito à política e à modernidade, mas que as chaves de interpretação comumente levam a essa conclusão equivocada. Segundo Bechelloni (1991, p. 66), hoje é possível ser italiano e moderno, mulher e militante político, meridional e italiano características antes incompatíveis -, mas, ao afirmá-lo, diz que esses novos indivíduos emergem "[...] do magma de uma sociedade que sempre se definiu em termos de pertencimento familiar, comunitário, religioso e ideológico muito mais do que em termos de pertencimento universal."

Assim, não obstante seu olhar seja otimista, os assuntos em discussão compreendem os objetos que também estão subjacentes aos escritos de outros, menos otimistas; isto é, não são abandonados o catolicismo, o regionalismo e a descentralização, o fantasma do passado, e a conclusão a que se chega é a de que, nesse contexto de busca pela modernidade e pelas razões por ainda não tê-la alcançado, rediscute-se a necessidade de aproximar a cultura e a população (RAIMONDI, 1998), abismo acusado por vários intelectuais, como Antonio Gramsci, e volta-se a discutir o caráter do italiano 
(FERRUCCI, 1993), atribuindo-lhe mais responsabilidade do que a de ser uma vítima da mediterraneidade, como de certa forma fizera Leopardi. Conforme sabido e mencionado, a literatura já fora instrumento de política de união; Raimondi (1998) propõe que seja também de identificação nacional porque é parte da cultura, da memória comum dos italianos, da narrativa que todos, mais ou menos, conhecem. Ferrucci herda a melancolia ou pessimismo ${ }^{10} \mathrm{de}$ Leopardi e, ainda que esteja contextualizado em outra época, culpa a história e o caráter dos italianos, e conclui que "desde o início e depois durante seu desenvolvimento, uma cultura inteira foi transformada em um gigantesco laboratório teatral".

o que fica evidente ao se olhar panoramicamente para estes escritos políticos é a manutenção, novamente, de temas e julgamentos sobre a identidade italiana, ainda que sejam novas as motivações e os objetivos, bem como os sujeitos que a discutem. Assim, nota-se que é constante a produção intelectual sobre o assunto por uma variedade de agentes e áreas do pensamento, e paradoxalmente, à primeira vista, vê-se uma constância também com relação aos temas e posições que tais textos veiculam - ainda que sejam, a depender do ponto de vista e do escopo textual, reformulados e atualizados, mas sempre subjacentes ao título identidade italiana.

Essa identificação de tipos de abordagens diferentes que se intitulam estudos sobre a identidade italiana não é facilmente alcançável sem que se proceda à observação de um número razoável de livros sobre o tema, como foi feito aqui, geralmente localizados entre a História, a Sociologia e a Política, mas não limitados a essas matérias. Aliás, as fronteiras entre estas três disciplinas parecem naufragar quando se opta por examinar a identidade italiana. Sociólogos apropriam-se das análises de material artístico (SORLIN, 1979, 2004), historicistas investigam a política e a caracterização italiana (DELLA LOGGIA, 1998), artistas inspiram-se na história (como Roberto Rossellini e Renato Guttuso), e assim delineia-se um lugar, um solo em que se encontram todos os discursos sobre a identidade italiana. Um solo em que estão fundamentados os enunciados a seguir:

[...] a tomada de consciência da nova realidade da Itália acontece e se define: em turnos, língua e literatura, artes visuais, experiência política, dimensão historiográfica [...] E o contexto da 'catolicidade' romana e carolíngia [...] da Europa latino-germânica que tem suas referência morais e ideológicas na Igreja e no Império, com as relativas problemáticas. (GALASSO, 2002, p. 71) 
[...] na Itália houve civilização (invenção artística, filosófica, jurídica, científico-tecnológica, de gosto) e riqueza, mas não potência: o exército, um príncipe e um cenário europeu favorável. Agora estava presente a última - a máquina bélica piemontesa, a monarquia de Turim, Cavour etc., mas as duas primeiras tinham desaparecido. (SCHIAVONE, 1998, p. 72)

[...] somos cosmopolitas porque individualistas. É raro que um italiano ajude outro italiano. (SEGRE apud FERRAROTTI, 1997, p. 114)

A identidade nacional confundiu-se com a fidelidade à "pequena pátria", ao localismo. Isto reflete-se também na literatura e na atividade artística. (SEGRE apud FERRAROTTI, 1997, p. 112)

Os italianos não "se juntam". São ao mesmo tempo angustiados pelo complexo de inferioridade com relação ao intelectual estrangeiro e agressivamente individualistas. (SEGRE apud FERRAROTTI, 1997, p. 115)

[...] o difundir-se de um neoindividualismo intimista, centrado na cultura do ego, nutrido por valores de iniciativa privada e particularistas, e, portanto, fundamentalmente indiferente, quando não até mesmo hostil, ao universalismo da ação pública. (SCIOLLA, 1990, p. 36)

[...] a difusa falta de espírito cívico foi historicamente vinculada a uma difusa incultura [...] $\mathrm{O}$ interesse intelectual das massas, seja por fatos políticos, pela cultura literária e até mesmo pela espiritualidade religiosa, continua a ser medíocre. (CERRONI, 2000, p. 12)

A Itália era uma intersecção de cultura até todo o século 18, a herdeira direta e reconhecida do patrimônio clássico grego e romano; depois, quando surgiram os Estados nacionais, a Itália, sem uma forte personalidade unitária do ponto de vista político, encontrou-se de repente indefesa, fraca também do ponto de vista cultural; com respeito à circulação internacional das ideias, descobriu-se impotente, deixada de fora. (FERRAROTTI, 1997, p. 115)

Esta sedimentação secular de uma comunidade de cultura traduz-se em particular no poderoso papel que tem na Itália a memória do mundo clássico, que é base da nossa cultura moderna, seja no uso 
literário prolongado por muito tempo pelo latim, seja na construção da própria cultura italiana. (CERRONI, 2000, p. 11)

[...] uma sociedade antiquíssima, trinta vezes secular, que garante ao italiano uma identidade sócio-antropológico-cultural fortíssima... (FERRAROTTI, 1997, p. 111)

[...] religião pré-cristã [...] formas de lealdade à família e ao clã, aos grupos de pseudo-parentesco, como a máfia. (SCIOLLA, 1990, p.)

[...] a falta de uma reforma religiosa, o que excluiu uma pluralidade religiosa consistente e retardou o processo de construção das liberdades modernas e da liberdade de religião. o fenômeno duplo da não unificação em Estado nacional e da falta de reforma religiosa tiveram uma outra consequência nos costumes dos italianos: a inconsistência de uma consciência política difusa e portanto o caráter particularista muito forte de suas relações, que ficaram centradas no grupo primário e nos horizontes de vida familiar e individualista. (CERRONI, 2000, p. 19)

$\mathrm{Na}$ Itália os dialetos têm raízes mais profundas, significados históricos que resistem a vida toda; não são folclore, são valores corporificados. (FERRAROTTI, 1997, p. 113)

Ainda no fim dos anos 1950 faltavam na Itália os atributos culturais unificadores, como a educação linguística generalizada e a consciência da própria cultura, os quais [...] caracterizam a formação das nações modernas. (SCIOLLA, 2000, p. 43)

[...] fragmentação do complexo econômico, escasso desenvolvimento social, pulverização linguística, provincialismo cultural [...] (BECHELLONI, 1991, p. 33)

Os enunciados expostos acima, bem como as referências em todo o corpo do texto, ilustram algumas das temáticas comuns ao material reunido - original de diversas áreas de conhecimento, mas que poderia ser recategorizado sob um mesmo endereço disciplinar fundamentado no que 
podemos chamar de formação discursiva ${ }^{11}$ da identidade italiana. Objetos discursivos comuns - a religiosidade, o caráter, a cultura, a política - que se repetem e reinventam através de retomadas deste assunto. Parece-nos importante investigar, uma vez demonstrada esta manutenção de temas e conceitos ligados a redes de saber, política e arte, o papel de uma rede enunciativa que é autocrítica, mas que, talvez, não ajude o país a abandonar sua própria sentença discursiva.

\section{REFERÊNCIAS}

ALPINI, S. Sociologia del cinema: i mutamenti della società italiana attraverso opere cinematografiche. Pisa: Edizioni ETS, 2008.

ANDERSON, B. Comunità immaginate. Tradução de Marco Vignale. Roma: Manifestolibri, 2005. ASOR ROSA, A. Genus italicum - Saggi sull'identità letteraria italiana nel corso del tempo. Torino: Einaudi, 1997.

BAUMAN, Z. Identidade - entrevista a Benedetto Vecchi. Rio de Janeiro: Jorge Zahar Ed., 2005. BECHELLONI, G. (Cur.). Identità italiana e modernizzazione. Percorsi controversi (1861-1990). Roma: Il Campo, 1991. [1987]

BERTELLI, S. (Cur.). La chioma della vittoria - Scritti sull'identità degli italiani dall'Unità alla Seconda Repubblica. Firenze: Ponte Alle Grazie, 1997.

BOLLATI, G. Litaliano. Il carattere nazionale come storia e come invenzione. Torino: Einaudi, 1983.

BRUNETTA, G. Identità italiana e identità europea nel cinema italiano dal 1945 al miracolo economico. Torino: Fondazione Giovanni Agnelli, 1996.

BUSSI, E. Canzoni per Adriana. La città e la provincia nel cinema di Antonio Pietrangeli. In: ; LEECH, P. (Cur.). Schermi della dispersione: cinema, storia e identità nazionale. Torino: Lindau, 2003. p. 281-300.

CAVALLO, P.; FREZZA, G. (Cur.). Le linee d'ombra dell'identità repubblicana: comunicazione, media e società in Italia nel secondo novecento. Napoli: Liguori, 2004.

CERRONI, U. Precocità e ritardo nell'identità italiana. Roma: Meltelmi, 2000.

CRAINZ, G. Storia del miracolo italiano - culture, identità, trasformazioni fra anni 50 e 60 . Roma: Donzelli Editore, 2005.

DE MAURO, T. Storia Linguistica dell'Italia unita. Roma: Laterza, 1983.

DE LUNA, G. Il concetto di identità nazionale in Italia nel XX secolo. In: CAVALLO, P; FREZZA, G. (Cur.). Le linee d'ombra dell'identità repubblicana: comunicazione, media e società in Italia nel secondo novecento. Napoli: Liguori, 2004. p. 21-34.

DELLA LOGGIA, E. G. L'identità italiana. Bologna: Il Mulino, 1998.

DI CIOMMO, E. I confini dell'identità. Teorie e modelli di nazione in Italia. Bari: Ragusa Grafica Moderna, 2004.

${ }^{11}$ Conceito de Michel Foucault cujas diretrizes são expostas em Foucault (2004). 
SCAMPARINI, J. DA LiterATURA AO CINEMA: UM PANORAMA DA ORIGEM À CONSOLIDAÇÃo...

FERRAROTTI, F. L'italia tra storia e memoria - Appartenenza e identità. Roma: Donzelli Editore, 1997.

FERRUCCI, F. Nuovo discorso sugli italiani. Con il discorso sopra lo stato presente degli italiani di Giacomo Leopardi. Milano: Mondadori, 1993.

FOUCAULT, M. A arqueologia do saber. Rio de Janeiro: Forense universitária, 2004.

GALASSO, G. L'Italia s' è desta - Tradizione storica e identità nazionale dal Risorgimento alla Repubblica. Firenze: Felice Le Monnier, 2002.

GINSBORG, P. Storia d'Italia dal dopoguerra a oggi. Torino: Einaudi 1989.

GIOANOLA, E. La letteratura italiana. Milano: LIBREX, 1985.

HALL, S. A identidade cultural na pós-modernidade. Rio de Janeiro: DP\&A, 2004.

HOBSBAWM, E. Nazioni e nazionalismi dal 1780 - Programma, mito, realtà. Tradução de Piero Arlorio. Torino: Einaudi, 2002.

; RANGER, T. (Cur.). L' invenzione della tradizione. Tradução de Enrico Basaglia. Torino: Einaudi, 2002.

LEOPARDI, G.. Il Discorso sopra lo stato presente degli italiani. In: FERRUCCI, F. Nuovo discorso sugli italiani. Milano: Mondadori, 1993. p. 81-163.

MESSINA, M. G. Lidentità dell'arte italiana. In: BERTELLI, S. (Cur.). La chioma della vittoria - Scritti sull'identità degli italiani dall'Unità alla Seconda Repubblica. Firenze: Ponte Alle Grazie, 1997. p. 99-128.

RAIMONDI, E. Letteratura e identità nazionale. Milano: Bruno Mondadori, 1998.

RAJAGOPALAN, K. Por uma lingüística crítica - Linguagem, identidade e a questão ética. São Paulo: Parábola Editorial, 2003.

REIS, S. Storia della lingua italiana. Rio de Janeiro, UFRJ, 1997.

RONCORONI, F. Lingua, storia e società - dall'inizio dell'Ottocento ai giorni nostri. Milano: Arnoldo Mondadori Editore, 1985.

SCHIAVONE, A. Italiani senza Italia - Storia e Identità. Torino: Einaudi, 1998.

SCIOLLA, L. Identità e mutamento culturale nell'Italia di oggi. In: CESAREO, V. (Cur.). La cultura dell'Italia contemporanea - Trasformazione dei modelli di comportamento e identità sociale. Torino: Fondazione Giovanni Agnelli, 1990. p. 35-69.

SORLIN, P. Sociologia del cinema. Milano: Garzanti, 1979.

. Cinema, identità, nazione. In: CAVALLO, P.; FREZZA, G. (Cur.). Le linee d'ombra dell'identità repubblicana: comunicazione, media e società in Italia nel secondo novecento. Napoli: Liguori, 2004. p. 7-20.

Submetido em: 03/11/2012

Aceito em: 13/02/2013 